\title{
PHYSICS-BASED INTRINSIC MODEL FOR AIGaN/GaN HEMTs
}

\author{
Shangli Wu*, Richard T. Webster** and A. F. M. Anwar* \\ *Electrical and Systems Engineering Department, University of Connecticut, \\ Storrs, CT 06269-2157 \\ ** Electromagnetics Technology Division, Air Force Research Laboratory \\ Hanscom AFB, MA 01730
}

MRS Internet J. Nitride Semiconductor Res. 4S1, G6.58 (1999)

\begin{abstract}
DC and intrinsic small signal parameters are reported for AlGaN/GaN high electron mobility transistors. The calculations are based upon a self-consistent solution of Schrödinger and Poisson's equation to model the quantum well formed in GaN. Transport parameters are obtained from an ensemble Monte Carlo simulation.
\end{abstract}

\section{INTRODUCTION}

AlGaN/GaN high electron mobility transistors (HEMTs) have recently attracted much attention with the large available band gap of the channel material $(\mathrm{GaN})$ and excellent thermal properties for possible applications in high power and high temperature microwave devices.

Some of the HEMT structures reported by Binari et. al. [1-2] and Redwing et. al. [3] had appreciable two dimensional electron gas (2DEG) concentration though the AlGaN supply layer was undoped. Dangling bonds at the $\mathrm{AlGaN} / \mathrm{GaN}$ heterointerface may give rise to interface charge that could explain the observed 2DEG concentration. Recently, an alternative explanation of the formation of the 2DEG concentration using the piezoelectric effect has been proposed by Asbeck et. al. [4]. However, as shown by the present authors [5] the calculation of 2DEG concentration as a function of $\mathrm{Al}$ mole fraction is in excellent agreement with the experimental data, even though the piezoelectric effect was not incorporated in the calculation.

The dc and small signal parameters and the rf performance can be investigated once the quantum well $(\mathrm{QW})$ properties and the transport properties of the channel material are known. In this paper the dc and small signal parameters are calculated using results obtained from an exact quantum calculation modeling the $\mathrm{QW}$ formed at the AlGaN/GaN heterointerface along with transport data obtained from an ensemble Monte Carlo simulation. The rf performance can then be obtained by evaluating the small signal model.

\section{THEORY}

The electron concentration, $\mathrm{n}_{\mathrm{s}}$, in the $\mathrm{QW}$ formed in $\mathrm{GaN}$ is determined by solving the Schrödinger and Poisson's equations self-consistently [5]. The calculated average distance of the electron cloud from the heterointerface, $\mathrm{x}_{\mathrm{avg}}$, and the position of the Fermi level, $\mathrm{E}_{\mathrm{F}}$, are expressed by the following functional forms and are used in the evaluation of the dc and small signal parameters $[6,7,8]$ :

$$
\mathrm{x}_{\mathrm{av}}=\mathrm{a}+\mathrm{b} \cdot \ln \left(\mathrm{n}_{\mathrm{s}}\right) \quad(\AA)
$$




$$
\mathrm{E}_{\mathrm{F}}=\mathrm{E}_{\mathrm{F}}(0)+\gamma \cdot \ln \left(\mathrm{n}_{\mathrm{s}}\right) \quad(\mathrm{eV})
$$

where the constants $\mathrm{a}, \mathrm{b}, \mathrm{E}_{\mathrm{F}(0)}$ and $\gamma$ are determined from the results of the quantum calculation. The drain-source current $\mathrm{I}_{\mathrm{ds}}$ can then be written as [5] :

$$
I_{d s}=\frac{G_{0}\left|V_{T}\right|^{2}}{\varepsilon_{0} L_{1}} \cdot\left(\frac{s}{2} \sqrt{s^{2}-p^{2}}-\frac{p^{2}}{2} \ln \left(\frac{s+\sqrt{s^{2}-p^{2}}}{p}\right)+\frac{\gamma}{\left|V_{T}\right|}\left[\sqrt{s^{2}-p^{2}}-p \cdot \cos ^{-1}\left(\frac{p}{s}\right)\right]\right.
$$

where $\mathrm{G}_{0}=\varepsilon \mathrm{Zv}_{\mathrm{s}} / \mathrm{d}_{\mathrm{eff}}, \quad \mathrm{d}_{\mathrm{eff}}=\mathrm{d}+\Delta \mathrm{d}$ with $\mathrm{d}$ and $\Delta \mathrm{d}$ being the thickness of AlGaN layer and effective channel thickness, respectively. $Z$ is the width of the gate and $L_{1}$ is the length of unsaturated region of the channel. The above equation incorporates the effect of the quantum well through eqs. 1 and 2 via reduced potentials, s and p. Also implicit in eq. 3 is the use of a velocity-electric field characteristic of the form $\mathrm{v}_{\mathrm{d}}=\mu_{0} E /\left(\left(\mathrm{v}_{\mathrm{s}} / \mu_{0}\right)^{2}+E\right)^{1 / 2}$ where $\mathrm{v}_{\mathrm{d}}$ is the drift velocity, $\mu_{0}$ is the low field mobility, $v_{\mathrm{s}}$ is the saturation velocity and $E$ is the electric field. The velocity-electric field characteristics are obtained from an ensemble Monte Carlo simulation using the following scattering mechanisms: acoustic phonon, optical phonon, intervalley, alloy, ionized impurity and piezoelectric scattering The evaluation of dc and small signal parameters follows the treatment presented in Ref. [5].

\section{RESULTS AND DISCUSSION}

The QW formed in $\mathrm{GaN}$ in an $\mathrm{Al}_{0.25} \mathrm{Ga}_{0.75} \mathrm{~N} / \mathrm{GaN}$ heterostructure is considered. The electron effective masses in GaN and AlN are assumed to be $0.19 \mathrm{~m}_{0}$ and $0.23 \mathrm{~m}_{0}$, respectively, where $\mathrm{m}_{0}$ is the free electron mass. The electron effective mass of $\mathrm{Al}_{\mathrm{x}} \mathrm{Ga}_{1-\mathrm{x}} \mathrm{Nis}$ obtained by a linear interpolation between the values for GaN and AlN. Based on a calculated valence band offset in $\mathrm{Al}_{\mathrm{x}} \mathrm{Ga}_{1-\mathrm{x}} \mathrm{N} / \mathrm{GaN}$, it is found that the conduction band offset may be given as: $\Delta \mathrm{E}_{\mathrm{c}}=0.75 \Delta \mathrm{E}_{\mathrm{G}}$, where $\Delta \mathrm{E}_{\mathrm{G}}$ is the difference in bandgaps of $\mathrm{GaN}$ and $\mathrm{Al}_{\mathrm{x}} \mathrm{Ga}_{1-\mathrm{x}} \mathrm{N}$ [5]. The temperature dependent bandgap for $\mathrm{GaN}$ is given as $\mathrm{E}_{\mathrm{G}}^{\mathrm{GaN}}(\mathrm{T})=3.056+5.08 \times 10^{-4} \mathrm{~T}^{2} /(\mathrm{T}-996)$ [9]. The bandgap of AlN is assumed to be $5.1 \mathrm{eV}$.

Fig.1 shows the conduction band profiles obtained by solving the Schrödinger and

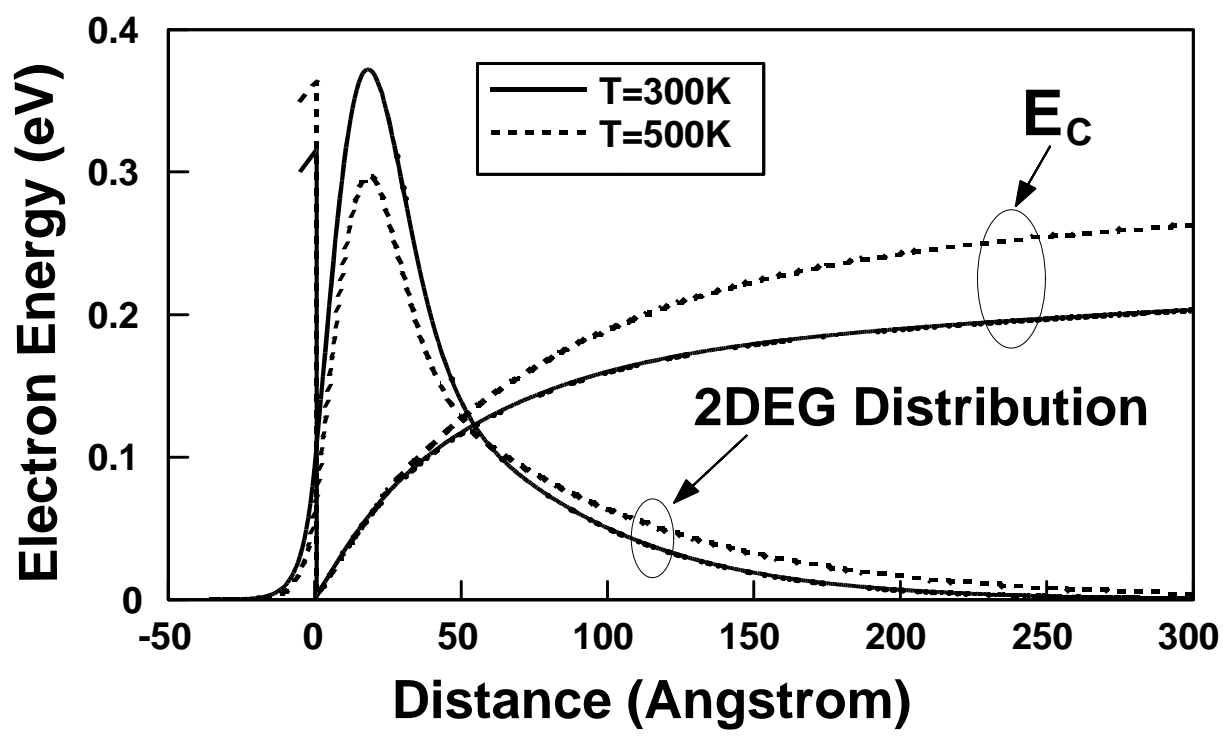

Fig. 1 Conduction band profile and 2DEG concentration at $300 \mathrm{~K}$ and $500 \mathrm{~K}$. 
Poisson's equations self-consistently for $300 \mathrm{~K}$ and $500 \mathrm{~K}$. On the same plot the 2DEG distributions are also plotted. The plots are obtained for a 2DEG concentration of $1.8 \times 10^{12} \mathrm{~cm}^{-2}$ and the corresponding positions of the Fermi level are $0.092 \mathrm{eV}$ and $0.052 \mathrm{eV}$ above the tip of the conduction band discontinuity at $300 \mathrm{~K}$ and $500 \mathrm{~K}$, respectively. The conduction band profiles can be explained by the fact that $n_{i}(300 \mathrm{~K})$ is 12 orders of magnitude less that $n_{i}(500 \mathrm{~K})$. This difference in $n_{i}$ is due to the higher effective density of states at higher temperatures and a decrease in bandgap of GaN with increasing temperature. Moreover, the conduction band offset increases from $0.313 \mathrm{eV}$ at room temperature to $0.361 \mathrm{eV}$ at $500 \mathrm{~K}$. Assuming fully ionized acceptors in $\mathrm{GaN}$ at both temperatures, the Fermi level moves closer to the intrinsic Fermi level at the higher temperature. Therefore, less band bending in $\mathrm{GaN}$ is required to obtain the same $2 \mathrm{DEG}$ concentration at $500 \mathrm{~K}$ that at $300 \mathrm{~K}$. At room temperature a higher fraction of the $2 \mathrm{DEG}$ concentration is in the first subband due to the close proximity of the Fermi level to the first eigen energy. On the other hand, at $500 \mathrm{~K}$ a larger separation between the first eigen energy and the Fermi level implies a lesser degree of occupation of the first subband, allowing the higher subbands to be populated.

In Fig. 2, the average distance of the electron cloud from the first heterointerface, $\mathrm{x}_{\mathrm{av}}$, and the position of the Fermi level, $\mathrm{E}_{\mathrm{F}}$, with respect to the tip of the conduction band are plotted as a function of the 2DEG concentration, $n_{s}$. At room temperature for $n_{s}>1 \times 10^{11} \mathrm{~cm}^{-2}, x_{a v}$ and $E_{F}$ can be expressed by the following relationships:

$$
\begin{gathered}
\mathrm{X}_{\mathrm{av}}=1740-104 \log _{10}\left(\mathrm{n}_{\mathrm{s}}\right) \AA \\
\mathrm{E}_{\mathrm{F}}=-5.232+0.4363 \log _{10}\left(\mathrm{n}_{\mathrm{s}}\right) \mathrm{eV}
\end{gathered}
$$

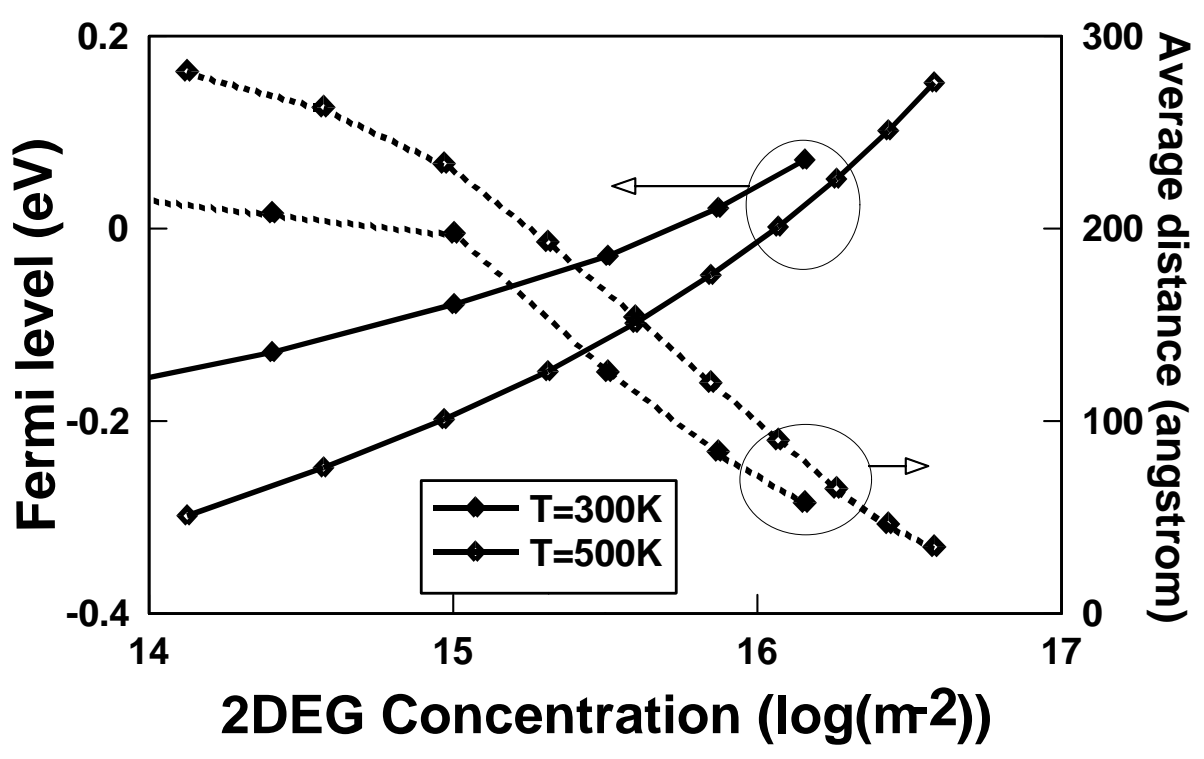

Fig. $2 \mathrm{x}_{\mathrm{av}}$ and $\mathrm{E}_{\mathrm{f}}$ as a function of the $2 \mathrm{DEG}$ concentration. 


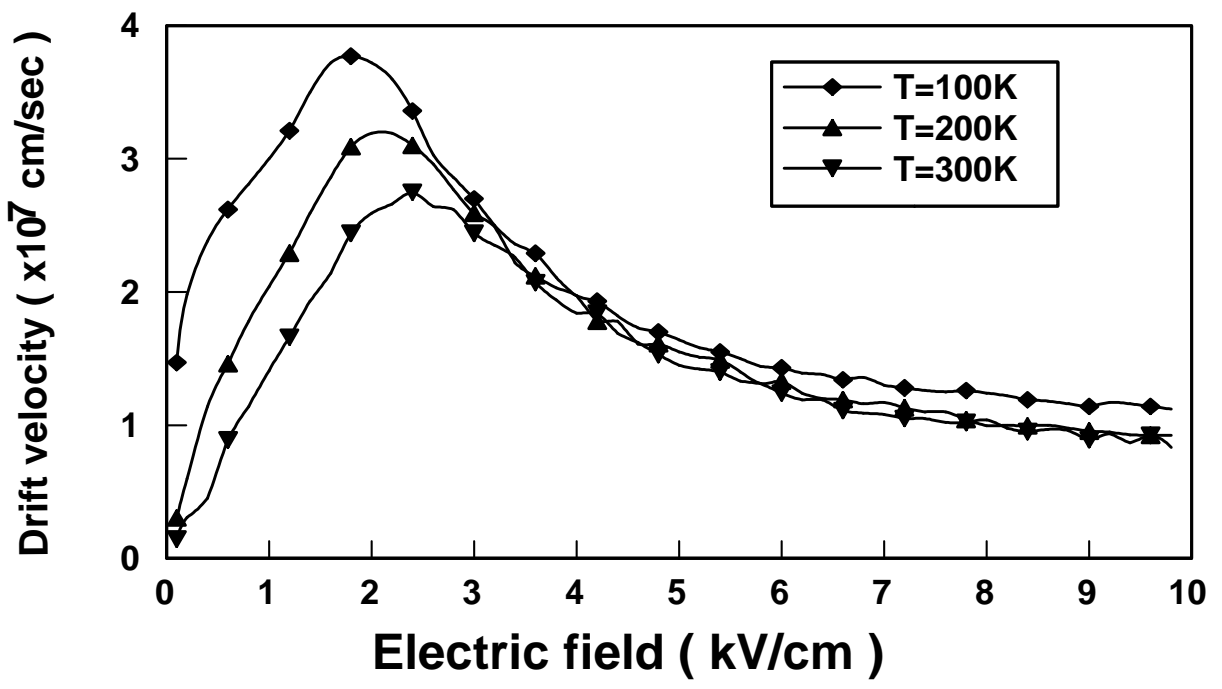

Fig. 3 Velocity-electric field characteristics for undoped GaN with temperature as a parameter.

The simulated electron drift velocity is plotted in Fig. 3 as a function of applied electric field in undoped bulk GaN with temperature as a parameter. A peak velocity of $2.6 \times 10^{7} \mathrm{~cm} / \mathrm{s}$ is obtained at a field strength of $145 \mathrm{kV} / \mathrm{cm}$ for undoped $\mathrm{GaN}$ at room temperature . The position of the peak velocity moves from $140 \mathrm{kV} / \mathrm{cm}$ at $100 \mathrm{~K}$ to $170 \mathrm{kV} / \mathrm{cm}$ at $500 \mathrm{~K}$. It is interesting that the low field mobility increases as the temperature is lowered, whereas, the saturation velocity does not show such a pronounced temperature dependence. This can be explained by noting that the low field mobility, which is dominated by acoustic phonons and polar optical phonon absorption, shows improvement due to the suppression of these scattering process at lower temperatures. The high field transport on the other hand, is dominated by polar optical phonon emission and intervalley scattering, both of which have a weak lattice temperature dependence. The room temperature low field mobility, $\mu$, obtained from the initial slope of the velocity field curves,

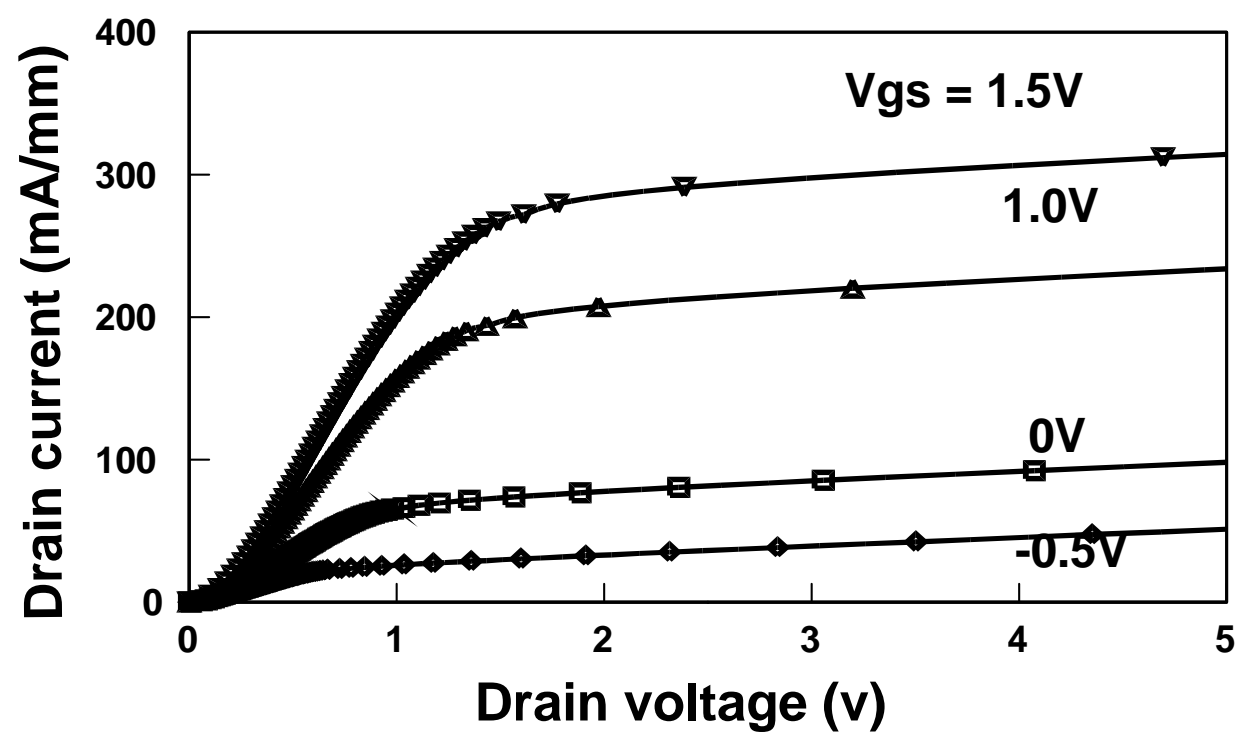

Fig. 4 DC current-voltage characteristics of AlGaN/GaN HEMT. 
changes from $590 \mathrm{~cm}^{2} / \mathrm{V}$-s at $1 \times 10^{17} \mathrm{~cm}^{-3}$ to $440 \mathrm{~cm}^{2} / \mathrm{V}-\mathrm{s}$ at $1 \times 10^{19} \mathrm{~cm}^{-3}$ for GaN. The simulations show that the temperature dependence of the low field mobility for a doping level of $1 \times 10^{17} \mathrm{~cm}^{-3}$ can be given as $\mu(\mathrm{T})=1156-2.75 \mathrm{~T}+0.002 \mathrm{~T}^{2} \mathrm{~cm}^{2} / \mathrm{V}-\mathrm{s}$. With increasing doping the peak in the low field mobility decreases and shifts towards higher temperature. This behavior is attributed to the strong influence of ionized impurity scattering.

The current voltage characteristics of a $1.2 \mu \mathrm{m}$ x $20 \mu \mathrm{m} \mathrm{Al}_{0.25} \mathrm{Ga}_{0.75} \mathrm{~N} / \mathrm{GaN}$ HEMT at room temperature are plotted in Fig. 4. A low field mobility of $600 \mathrm{~cm}^{2} / \mathrm{V}$-s and a saturation velocity of $1 \times 10^{7} \mathrm{~cm} / \mathrm{s}$ are assumed for the undoped GaN channel. The AlGaN epilayer thickness is assumed to be $220 \AA$. The threshold voltage is calculated to be $-3.75 \mathrm{~V}$, and the barrier potential, $\varphi_{\mathrm{b}}=1.1 \mathrm{eV}$.

In Fig. 5, the saturation drain current and the transconductance of a $1.2 \mu \mathrm{m}$ x $20 \mu \mathrm{m}$ gate HEMT are plotted as a function of the gate-source potential at $\mathrm{V}_{\mathrm{ds}}=2.0 \mathrm{~V}$. A transconductance of $100 \mathrm{mS} / \mathrm{mm}$ is obtained at $\mathrm{V}_{\mathrm{gs}}=2.0 \mathrm{~V}$. In Fig 5 (b), the small signal gate capacitance and the drain resistance are shown. These small signal parameters predict a maximum unity current gain
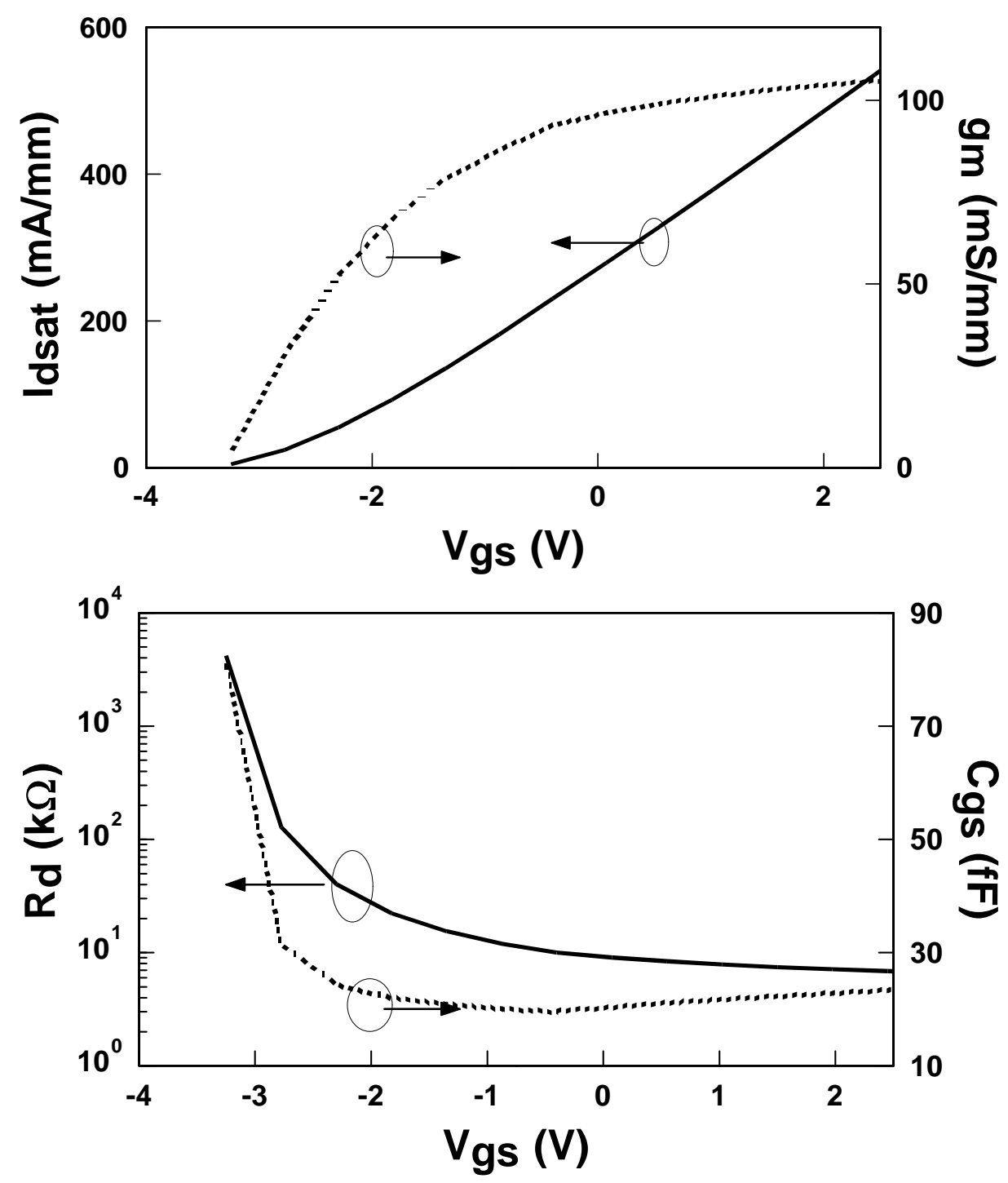

Fig. 5 (a) Saturation drain current and transconductance (b) drain resistance and gate-source capacitance are plotted as a function of gate bias. 
cutoff frequency, $\mathrm{f}_{\mathrm{T}}$, of $12 \mathrm{GHz}$ at room temperature that reduces to $10 \mathrm{GHz}$ at $500 \mathrm{~K}$.

\section{CONCLUSION}

A physics based intrinsic model for $\mathrm{AlGaN} / \mathrm{GaN}$ HEMTs has been presented. The model is based a self-consistent solution the Schrödinger and Poisson's equations as well as channel material transport properties obtained from a Monte Carlo simulation. The resulting small signal model predicts a high transconductance of $100 \mathrm{mS} / \mathrm{mm}$ with a unity current gain cutoff frequency of $12 \mathrm{GHz}$. Transistors with these characteristics will be useful in microwave applications at high temperatures.

\section{ACKNOWLEDGMENTS}

The authors acknowledge support from the Air Force Office of Scientific Research and the Expert Science and Engineering Program under Air Force Research Laboratory contract number F30602-97-C-0199. This work was supported in part by a grant of High Performance Computer (HPC) time from the DOD HPC Center, Air Force Aeronautical Systems Center (ASC), Cray C90.

\section{REFERENCE}

[1].S. C. Binari, J. M. Redwing, G. Kelner and W. Kruppa, Electron. Lett., vol. 33, No. 3, p. 242, 1997.

[2].S. C. Binari, Electrochem. Soc. Proc., 95-21, p. 136, 1995.

[3].J. M. Redwing, M. A. Tischler, J. S. Flynn, S. Elhamri, M. Ahoujja, R. S. Newrock and W. C. Mitchel, Appl. Phys. Lett., vol. 69, p. 963, 1996

[4].P. M. Asbeck, E. T. Yu, S. S. Lau, G. J. Sullivan, J. Van Hove and J. Redwing, Electron. Lett., p. 241, Aug. 1997.

[5].R. T. Webster and A.F.M. Anwar, MRS Proc. vol. 428, p.929, 1997.

[6].M. A. Khan, Q. Chen, M. S. Shur, B. T. Dermott and J. A. Higgins, IEEE Electron Dev. Lett., vol. 17, No.7, p. 325, 1996.

[7].M. S. Shur and M. A. Khan, MRS Bull., p. 44, Feb., 1997

[8].J. M. Redwing, M. A. Tischler, J. S. Flynn, S. Elhamri, M. Ahoujja, R. S. Newrock and W. C. Mitchel, Appl. Phys. Lett., vol. 69, p. 963, 1996

[9].S. Strite and H. Morkoc, J. Vac. Sci. Technol., vol. B 10, No. 4, p. 1237, 1992. 